\title{
Assessing the effect of soil parameterization in land use change impact modeling
}

\author{
Yacouba Yira ${ }^{1,2}$, Aymar Yaovi Bossa ${ }^{2,3}$, Ernest Amoussou ${ }^{4}$, Djigbo Félicien Badou ${ }^{5,2}$, Jean Hounkpè ${ }^{3,2}$, \\ and Kpade Ozias Laurentin Hounkpatin ${ }^{6,2}$ \\ ${ }^{1}$ Applied Science and Technology Research Institute - IRSAT/CNRST, \\ P.O. Box 7047, Ouagadougou, Burkina Faso \\ ${ }^{2}$ Hydro-Climate Services, P.O. Box 374, Ouagadougou 14, Burkina Faso \\ ${ }^{3}$ Department of Water for Agriculture and the Society, National Institute of Water, \\ University of Abomey-Calavi, P.O. Box 526, Cotonou 01, Benin \\ ${ }^{4}$ Département de Géographie et Aménagement du Territoire de l'Université de Parakou, BP 123 Parakou, Benin \\ ${ }^{5}$ Ecole d'Horticulture et d'Aménagement des espaces Verts, \\ Université Nationale d'Agriculture, BP 43 Kétou, Benin \\ ${ }^{6}$ Department of Soil and Environment, Swedish University of Agricultural Sciences, \\ P.O. Box 7014, 75007, Uppsala, Sweden \\ Correspondence: Yacouba Yira (yira_y@uni-bonn.de) \\ Published: 16 November 2021
}

\begin{abstract}
This study addresses the importance of integrating the effect of land use on soil infiltration rate into land use change impact modeling. Based on a validated version 9.05.04 of the Water balance Simulation Model-WaSiM (statistical quality measures $>0.7$ ), and field measurement of the infiltration rate under cropland and fallow, sixteen model simulations were performed. The impact of land use change is computed comparing LULC status of years 1990 and 2013. The effect of soil parameterization is computed using a refined soil map integrating land use change impact of soil infiltration rate and a classic soil map not considering this interaction. The results show differences in model results as an effect of soil parameterization approaches, indicating that the model is sensitive to the integration of LULC related effects on soil hydraulic conductivity. These differences are more pronounced with increasing modeling time steps $(24$ and $28 \mathrm{~h}$ ). The signal-to-noise-ratio indicates that, results achieved in LULC impact assessment with a classic and a refined soil parameterization are very comparable except for interflow.
\end{abstract}

\section{Introduction}

Land use change impact is a major research topic in hydrology (Wagner et al., 2017). By affecting the partitioning of precipitation and influencing many hydrological process, land use and land cover (LULC) changes strongly affect the quality and quantity of water resources (Aghsaei et al., 2020). However, quantifying the net effect of LULC change impact on water resources remains challenging, as this effect is multifactorial (Yira et al., 2016), and includes a modeling approach component (Beven, 2012). Besides the modeling objective, a modeling approach often heavily relies on data availability.

Field evidences, by Yira and Bossa (2019), of land use impacts on soil infiltration rate provide the opportunity to assess the importance of considering land use dependent soil properties in the hydrological impact assessment of LULC change on water resources in the Dano catchment. A modeling exercise incorporating knowledge gained from field investigations with regards to land use impacts on soil infiltration rate may require additional parameterization effort, but the method has proven to improve hydrological processes representation (Hölzel and Diekkrüger, 2010). 

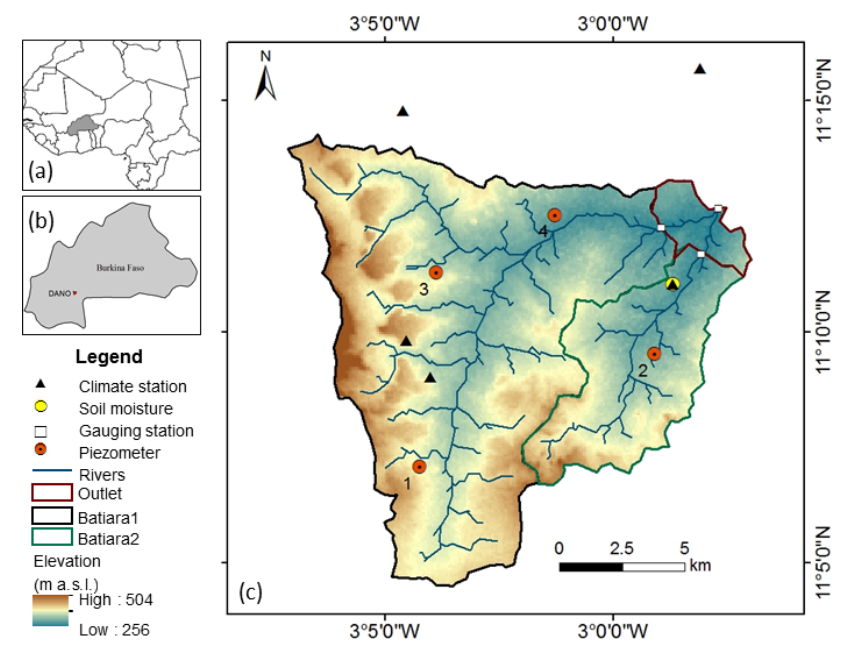

Figure 1. Location and instrumentation map of the Dano catchment.

The current study addresses the importance of integrating the influence of land use on soil infiltration rate into land use change impact assessment. It aims to analyze how soil parameterization and modeling time step could affect the results in land use change impact assessment. It has the following specific objectives: (i) assess the sensitivity of the hydrological simulation model to land use effect on soil infiltration rate, (ii) assess the consequences of integrating land use effect on soil infiltration rate in LULC impact assessment, and (iii) to evaluate whether the importance of integrating land use related effect on soil infiltration rate in the modeling exercise depend on the modeling time step.

\section{Materials and methods}

\subsection{Study area}

The study was carried out in the Dano catchment (Fig. 1). The catchment is located is in the Sudanese climate zone of Burkina Faso and covers an area of $195 \mathrm{~km}^{2}$. It is characterized by an alternation of two seasons including a dry season of 6 to 7 months (November to April) and a rainy season of 5 months spanning from May to October (Yira et al., 2016). The natural vegetation of the catchment is of Sudanian region. Average monthly temperatures and annual rainfall range between 24 and $32^{\circ} \mathrm{C}$, and 800 to $1200 \mathrm{~mm} \mathrm{yr}^{-1}$, respectively (Yira et al., 2016).

\subsection{Land use change}

The land use and land cover maps after Forkour (2014) and Landmann et al. (2007) corresponding to LULC status for the years 2013 and 1990 respectively, were used for LULC change impact assessment (Table 1). The reclassified version of both maps (Yira et al., 2016) was used, and the year 1990 was considered as baseline.
Table 1. Percentage of the catchment area per land use class in 1990 and 2013.

\begin{tabular}{lrr}
\hline Land use class & \multicolumn{2}{c}{ Years } \\
\cline { 2 - 3 } & 1990 & 2013 \\
\hline Cropland (\%) & 11.6 & 38 \\
Savannah (\%) & 87 & 58 \\
Water (\%) & 0.05 & 0.05 \\
Urban area (\%) & 1 & 3 \\
\hline
\end{tabular}

\subsection{Infiltration measurement}

A hood infiltrometer (Schwärzel and Punzel, 2007) was used to perform infiltration $\left(K_{\mathrm{S}}\right)$ tests on adjacent croplands and fallow areas. Measurements showed on average (1.16-fold) higher $K_{\mathrm{S}}$ under fallow compared to cropland (Yira and Bossa, 2019).

\subsection{Soil map refinement}

Soil infiltration rate is parameterized in WaSiM through the soil map and soil classes' characteristics, while no infiltration rate dependent parameter is associated with this parameterization. Following the infiltration test, the Eq. (1) by Hölzel and Diekkrüger (2010) was adopted to integrate land use influence on $K_{\mathrm{S}}$ into the soil parameterisation.

$K_{\mathrm{s}_{x_{i}}}^{\mathrm{ref}}=K_{\mathrm{sat}}^{\mathrm{map}} \cdot \frac{\hat{K}_{\mathrm{s}_{x_{i}}}^{\text {meas }}}{\hat{K}_{\mathrm{s}_{x}}^{\text {meas }}}$

where $\hat{K}_{\mathrm{S}}$ is the mean of the infiltration rate, $x$ refers to all samples, $x_{i}$ is the samples of the specific area (cropland or savannah), "ref" refers the refined values, "meas" refers to measured values, and "map" indicates the initial values given by the classic soil map.

The reference basis for $K_{\mathrm{S}}$ was provided by the $K_{\mathrm{S}}$ values from the classic soil map (CS), which were derived from laboratory measurements for each soil type and different soil horizons following Saxton and Rawls (2006).

\subsection{Modeling approach and simulation experiment}

Version 9.05.04 of WaSiM, after Yira et al. (2016) and Schulla (2015), calibrated and validated (Fig. 2) at a daily time step using a classic soil parameterization and the LULC map of 2013 was the starting point of the study.

The impact of land use change is computed comparing LULC status of years 1990 and 2013. Two additional factors are considered; i.e. (i) the interaction between soil and land use parameterization (with a soil parameterization integrating LULC dependent soil infiltration rate (refined soil-RS), and a classic soil parameterization ignoring this dependance (classic soil-CS), and (ii) the influence of the modeling time 


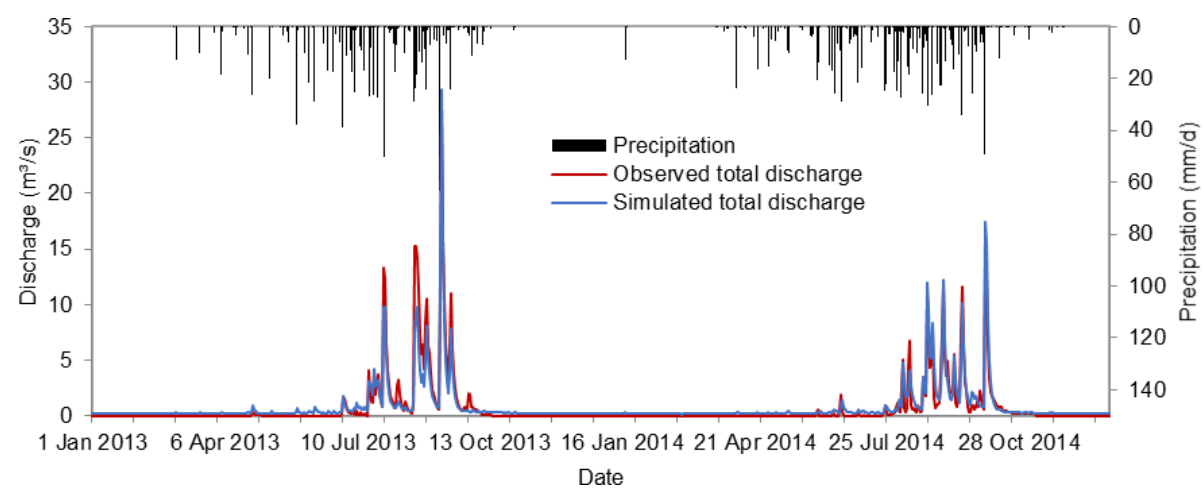

Figure 2. Daily observed and simulated discharges for the calibration (2013) and validation (2014) years at the outlet of the Dano catchment.

Table 2. Combined land use scenarios, soil parameterizations and time scales experiments.

\begin{tabular}{|c|c|c|c|c|c|c|c|}
\hline \multicolumn{4}{|c|}{ Classic soil (CS) } & \multicolumn{4}{|c|}{ Refined soil (RS) } \\
\hline \multicolumn{8}{|c|}{ Land use status 2013 (LU2013) } \\
\hline 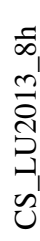 & 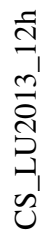 & 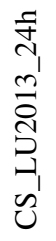 & 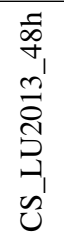 & 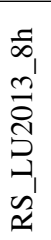 & 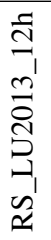 & 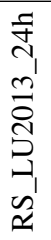 & 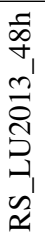 \\
\hline \multicolumn{8}{|c|}{ Land use status 1990 (LU1990) } \\
\hline 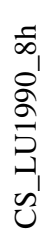 & 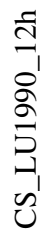 & 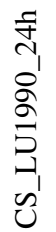 & 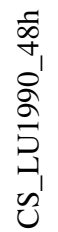 & 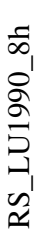 & 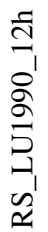 & 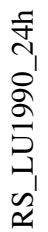 & 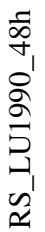 \\
\hline
\end{tabular}

$\mathrm{SNR}=\left[\frac{\left|X_{\mathrm{CS} \_L U 1990}-X_{\mathrm{CS} \_L U 2013}\right|}{\left|X_{\mathrm{CS} \_L U 1990}-X_{\mathrm{RS} \_L U 1990}\right|}\right]-1$

where SNR is the "signal-to-noise-ratio", $X$ is the simulated variable (discharge, $\mathrm{ET}_{\mathrm{a}}$, etc.).

\section{Results and discussion}

\subsection{Modeling time step and model performance}

The initial model, calibrated and validated at a daily time step using a classic soil parameterization and the LULC of 2013 (CS_LULC2013_24h), and the other seven model set ups using the same LULC map but different soil parameterizations and time steps (see Table 2) are compared to the observed discharge in order to relate change in model performance to soil parameterization and time step (Fig. 3). The annual variation of discharge appears well reproduced by each model set up, although difference in simulated peak discharges can be noticed.

Soil refinement appears beneficial to all simulations perstep on this interaction $(8,12,24$, and $48 \mathrm{~h}$ time steps). Overall, 16 model configurations were set up combining these two factors and LULC status (Table 2). The fitted calibrated parameters of the initial model (Yira et al., 2016) were kept constant for all the simulations experiments.

\subsection{Comparison of land use and soil parameterization effects}

The "signal-to-noise-ratio" (SNR) (Bormann et al., 2009) was adapted to compare LULC change impacts with soil parameterizations effects (Eq. 2). In this study, the "noise" is represented by soil parameterization effect, and "signal" is represented by land use change impact. Positive SNR values indicate that land use change impacts are larger than soil parameterization effects and Negative SNR values imply the opposite. formed at 8, 12 and $48 \mathrm{~h}$ time steps irrespective of the considered model statistical quality measure; this may suggest that refined $K_{\mathrm{S}}$ is more effective than classic $K_{\mathrm{s}}$. However, at the $24 \mathrm{~h}$ time step, classic soil (CS) outscores refined soil (RS) for Pearson product-moment-correlation-coefficient.

\subsection{Modeling time step and water balance}

Time step effects on water balance components are shown in Fig. 4. Change in water balance components with increasing modeling time step comparing land use status of 2013 and 1990 are very similar: (i) an increase of actual evapotranspiration, (ii) a decrease in total discharge, (iii) a decrease in surface runoff, (iv) an increase in baseflow, (v) a decrease in interception, and (vi) an increase followed by a decrease for interflow.

The comparison of RS and CS histograms for the same time step shows the effect of soil parameterization on dis- 

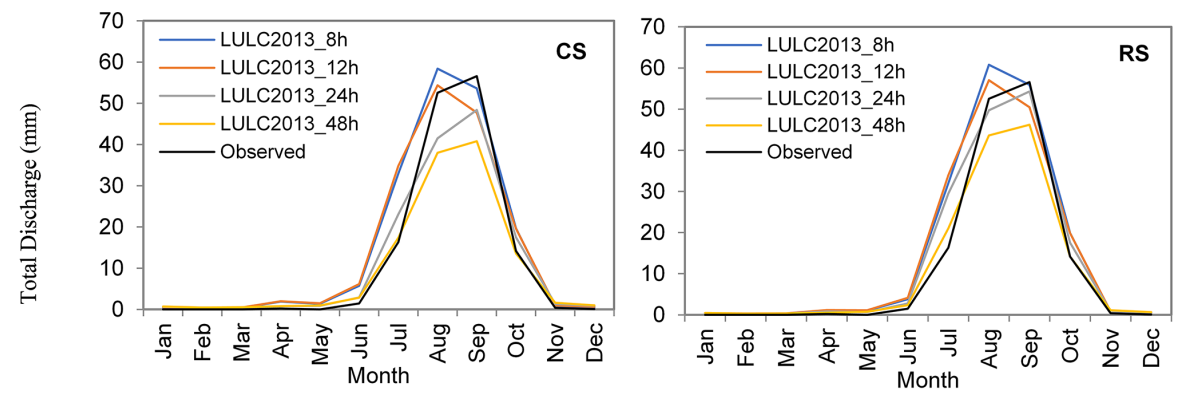

\begin{tabular}{|l|c|c|c|c|c|c|c|c|}
\cline { 2 - 10 } \multicolumn{1}{c|}{} & \multicolumn{3}{c|}{ CS } & \multicolumn{4}{c|}{ RS } \\
\cline { 2 - 10 } \multicolumn{1}{c|}{} & $8 \mathrm{~h}$ & $12 \mathrm{~h}$ & $24 \mathrm{~h}$ & $48 \mathrm{~h}$ & $8 \mathrm{~h}$ & $12 \mathrm{~h}$ & $24 \mathrm{~h}$ & $48 \mathrm{~h}$ \\
\hline $\mathrm{R}^{2}$ & 0.90 & 0.83 & 0.94 & 0.98 & 0.92 & 0.87 & 0.93 & 0.97 \\
\hline NSE & 0.92 & 0.90 & 0.95 & 0.90 & 0.93 & 0.91 & 0.96 & 0.96 \\
\hline KGE & 0.69 & 0.69 & 0.82 & 0.76 & 0.71 & 0.72 & 0.82 & 0.86 \\
\hline
\end{tabular}

Figure 3. Model performance using different modeling time steps and soil parameterization approaches. Period of January 2013 to December 2014. Performance is calculated using mean monthly discharges.

charge components. For all simulation time steps, total discharge and discharge components clearly appear sensitive to soil parameterization.

Consequences of LULC conversion from year 1990 to 2013 are the reduction of LAI, vegetation cover fraction, root depth etc. which leads to the increase of throughfall and the reduction of water that is evaporated by interception. Therefore, more water can infiltrate into the soil or flow as infiltration excess runoff. Interflow and baseflow increase with throughfall.

Change in the water balance between classic soil and refined soil parameterization has to be interpreted solely by the difference in hydraulic conductivity at the soil surface, as this is the only difference between CS and RS. Change in hydraulic conductivity at the uppermost numerical soil layer due to soil refinement leads CS and RS to partition throughfall differently which affects surface runoff generation and water balance

\subsection{Soil refinement and land use change impact}

Figure 5 presents the change in the water balance components due to LULC change (LULC of 1990 compared to LULC of 2013) following a classic soil parameterization (Fig. 5a) and a refined soil parameterization (Fig. 5b). A very comparable decrease in actual evapotranspiration and an increase in discharge (all components) characterize LULC change impacts for both soil parameterization approaches. However, differences in the water balance components between soil parameterization approaches can be noticed as shown by Fig. 5c. These differences vary with the modeling time step and water balance components. A LULC change impact assessment performed with a classic soil leads to a higher decrease in $\mathrm{ET}_{\mathrm{a}}$ compared to an assessment performed with a refined soil; this difference appears to further increase with the modeling time step. Increase in surface runoff following LULC change is higher with the RS than the CS.
Furthermore, the difference in surface runoff between RS and CS decreases with the modeling time step. Simulated change in total discharge, baseflow and interflow following LULC change are lower with the refined soil compared to the classic soil.

It can be noted from Fig. $5 c$ that irrespective of modeling time step, a LULC change impact assessments performed with a RS and CS parameterization do not yield the same water balance. Differences range from 0.2 to $18 \mathrm{~mm} \mathrm{yr}^{-1} \mathrm{de}-$ pending on water balance components. Figure 5 further indicates that simulated changes in water balance due to LULC change are larger than the change due to soil parameterization, suggesting that soil refinement might have a marginal impact in LULC impact assessment.

The SNR is calculated to test whether the LULC change effect (Table 3) is significantly larger than the soil refinement effect. Table 3 shows both positive and negative SNR. Except interflow, all water balance components show positive SNR, indicating that LULC change impact is larger than soil refinement, meaning the noise created by soil refinement does not affect LULC change signal. In other words, results achieved in LULC impact assessment with both soil parameterizations (CS and RS) are very comparable except for interflow. Noise is larger than signal only for simulations performed at 24 and $48 \mathrm{~h}$, even though this noise is low. Therefore, for a LULC impact assessment focusing on discharge components it is necessary to use a refined soil as omitting this information produced an effect higher than LULC change effect. However, LULC change impact appears larger than soil refinement effect for the water balance, as confirmed by positive SNR indices. It is noteworthy that for interflow, soil refinement effect was larger than the LULC change impact for some modeling time steps, implying that a consistent assessment of LULC change impact on interflow (and consequently, on discharge components) should integrate LULC related effects into soil properties. 

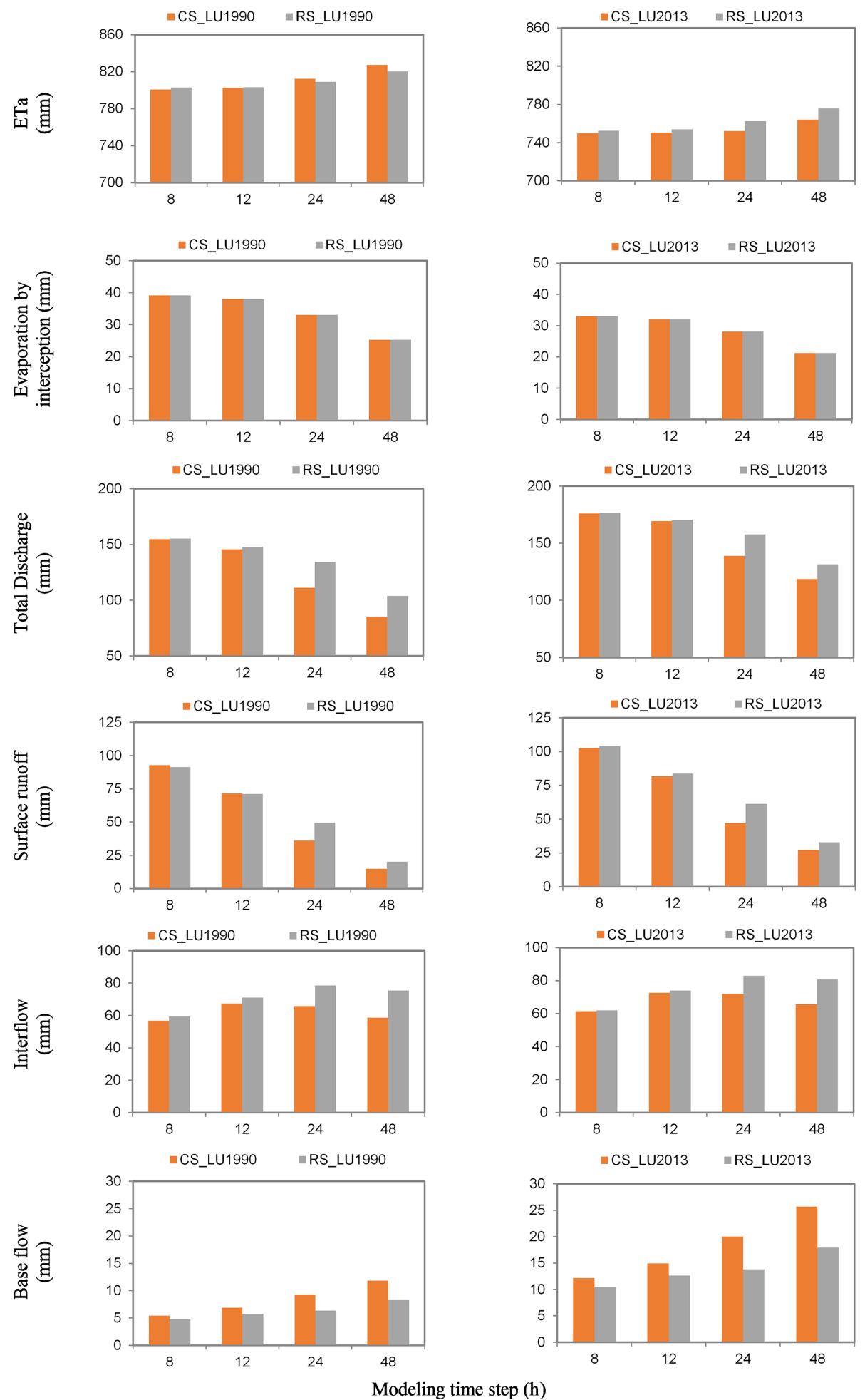

Figure 4. Annual water balance components for different modeling time steps and soil parameterization approaches for the period of January 2013 to December 2014. 


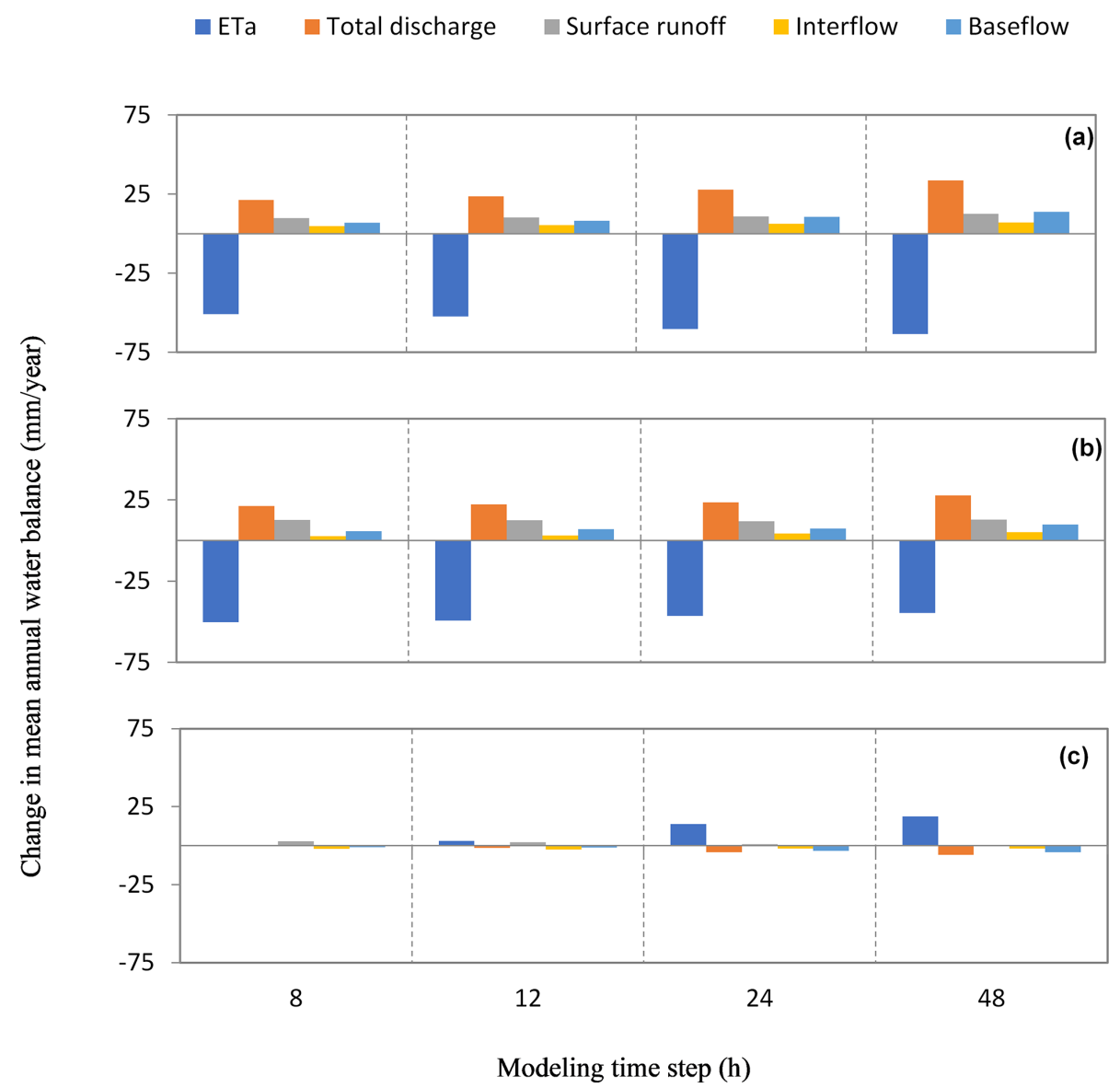

Figure 5. Change in water balance as a result of LULC change, modeling time step and soil parameterization. Part (a) compares LULC1990 to LULC2013 using a classic soil-CS, part (b) compares LULC1990 to LULC2013 using a refined soil-RS, and (c) shows the difference between soil parametrization approaches $(\mathbf{a}, \mathbf{b})$.

Table 3. Signal-to-noise ratio for different modeling time steps. Signal refers to LULC change effect, and noise is soil refinement effect.

\begin{tabular}{lrrrrr}
\hline & \multicolumn{5}{c}{ Signal to noise ratio } \\
\cline { 2 - 6 } $\begin{array}{l}\text { Modeling } \\
\text { time step }\end{array}$ & $\begin{array}{r}\text { Actual } \\
\text { evapotranspiration }\end{array}$ & $\begin{array}{r}\text { Total } \\
\text { discharge }\end{array}$ & $\begin{array}{r}\text { Surface } \\
\text { runoff }\end{array}$ & Interflow & $\begin{array}{l}\text { Base } \\
\text { flow }\end{array}$ \\
\hline 8 & 22.91 & 39.83 & 5.94 & 0.82 & 9.61 \\
12 & 69.76 & 9.35 & 27.51 & 0.42 & 6.20 \\
24 & 17.18 & 0.20 & 0.07 & -0.52 & 2.63 \\
48 & 8.13 & 0.81 & 1.34 & -0.58 & 2.86 \\
\hline
\end{tabular}

\section{Conclusion}

In this study, land use change related effects on soil infiltration rate was integrated in the modeling of LULC change impact on the Dano catchment hydrology. Previous field investigation showed that soil surface hydraulic conductivity was significantly affected by land use. This additional information was integrated in the modeling as refined soil, and was compared to a simulation ignoring this information. Mod- eling time step was further considered as a potential factor affecting the model outputs. Several models were then set up combining soil parameterization, modeling time step, and LULC change.

The results show that trends in water balance and discharge components following LULC change was similar for classic and refined soil parameterization irrespective of the modeling time step. However, differences in model results could be observed between soil parameterization approaches, indicating that the model is sensitive to the integration of LULC related effects on soil hydraulic conductivity. This supports the idea that integrated land use related effects on soil properties renders LULC change scenarios more plausible.

Code availability. WaSIM code is not publicly accessible. The applied Richards version of the software is available for download at http://www.wasim.ch/en/products/wasim_richards.htm (last access: 7 October 2021) (WaSiM-ETH, 2021). 
Data availability. The applied data are available on the WASCAL Geoportal (https://wascal-dataportal.org/geonetwork/apps/ search/?east_collapsed $=$ true\&s_search $=\&$ s_timeType $=$ true \&s_ scaleOn=false\&s_E_hitsperpage $=20$, last access: 7 October 2021) (WASCAL Geoportal, 2021).

Author contributions. YY, AYB and EA developed the concept. All authors contributed to implementing the concept and writing the manuscript.

Competing interests. The contact author has declared that neither they nor their co-authors have any competing interests.

Disclaimer. Publisher's note: Copernicus Publications remains neutral with regard to jurisdictional claims in published maps and institutional affiliations.

Special issue statement. This article is part of the special issue "Hydrology of Large River Basins of Africa". It is a result of the 4th International Conference on the "Hydrology of the Great Rivers of Africa", Cotonou, Benin, 13-20 November 2021.

Acknowledgements. The authors are grateful to Bernd Diekkrüger for supervising this work.

\section{References}

Aghsaei, H., Mobarghaee D. N., Moridi, A., Asadolahi, Z., Delavar, M., Fohrer, N., and Wagner, P. D.: Effects of dynamic land use/land cover change on water resources and sediment yield in the Anzali wetland catchment, Gilan, Iran, Sci. Total Environ., 712, 136449, https://doi.org/10.1016/j.scitotenv.2019.136449, 2020.

Beven, K.J.: Rainfall-Runoff Modelling: The Primer, 2nd Edition, 2nd ed. John Wiley \& Sons, Ltd, Lancaster, England, 2012.

Bormann, H., Breuer, L., Gräff, T., Huisman, J. A., and Croke, B.: Assessing the impact of land use change on hydrology by ensemble modelling (LUCHEM) IV: Model sensitivity to data aggregation and spatial (re-) distribution, Adv. Water Resour., 32, 171192, https://doi.org/10.1016/j.advwatres.2008.01.002, 2009.
Forkour, G.: Agricultural Land Use Mapping in West Africa Using Multi-sensor Satellite Imagery, PhD Thesis, Julius-MaximiliansUniversität Würzburg, Germany, available at: http://opus. uni-wuerzburg.de/files/10868/Thesis_Gerald_Forkuor_2014.pdf (last access: 6 June 2019), 2014.

Hölzel, H. and Diekkrüger, B.: Hydrological Analyses as a Prerequisite for Soil Erosion Modeling - Landscape Related Studies in a Mesoscale Hydrological Catchment, in: Landform - Structure, Evolution, Process Control, Lecture Notes in Earth Sciences, edited by: Otto, J.-C. and Dikau, R., Springer, Berlin, Heidelberg, 127-149, 2010.

Landmann, T., Herty, C., Dech, S., and Schmidt, M.: Land cover change analysis within the GLOWA Volta basin in West Africa using 30-meter Landsat data snapshots, in: Geoscience and Remote Sensing Symposium, 23-27 July 2007, Barcelona, Spain, https://doi.org/10.1109/IGARSS.2007.4424058, 2007.

Saxton, K. E. and Rawls, W. J.: Soil water characteristic estimates by texture and organic matter for hydrologic solutions, Soil Sci. Soc. Am. J., 70, 1569-1578, 2006.

Schwärzel, K. and Punzel, J.: Hood Infiltrometer - A New Type of Tension Infiltrometer, Soil Sci. Soc. Am. J., 71, 1438, https://doi.org/10.2136/sssaj2006.0104, 2007.

Schulla, J.: Model DescriptionWaSiM, available at: http:// wasim.ch/downloads/doku/wasim/wasim_2015_en.pdf (last access: 17 June 2016), 2015.

Wagner, P. D., Bhallamudi, S. M., Narasimhan, B., Kumar, S., Fohrer, N., and Fiener, P.: Comparing the effects of dynamic versus static representations of land use change in hydrologic impact assessments, Environ. Model. Softw., 122, 103987, https://doi.org/10.1016/j.envsoft.2017.06.023, 2017.

WASCAL Geoportal: https://wascal-dataportal.org/geonetwork/ apps/search/?east_collapsed=true \&s_search=\&s_timeType $=$ true\&s_scaleOn=false\&s_E_hitsperpage $=20, \quad$ last access: 7 October 2021.

WaSiM-ETH: WaSiM (Richards) [code], available at: http://www. wasim.ch/en/products/wasim_richards.htm, last access: 7 October 2021.

Yira, Y. and Bossa, A. Y.: Agricultural Expansion-Induced Infiltration Rate Change in a West African Tropical Catchment, Appl. Environ. Soil Sci., 2019, 2434512, https://doi.org/10.1155/2019/2434512, 2019.

Yira, Y., Diekkrüger, B., Steup, G., and Bossa, A. Y.: Modeling land use change impacts on water resources in a tropical West African catchment (Dano, Burkina Faso), J. Hydrol., 537, 187199, https://doi.org/10.1016/j.jhydrol.2016.03.052, 2016. 